\title{
GENETIC DISSECTION OF HETEROSIS AND COMBINING ABILITY IN CASTOR (Ricinus communis L.) WITH LINE $\times$ TESTER ANALYSIS
}

\author{
A. A. Punewar, A. S. Patil ${ }^{*} \dagger$, H. R. Nandanwar, S. M. Patel and B. N. Patel \\ Department of Genetics and Plant Breeding,Anand Agricultural University, Anand-388 110, Gujarat, India. ${ }^{\dagger}$ Present Address: Plant Sciences Institute, ARO-the \\ volcani centre, Rishon Lezion- 15 159, Israel
}

Received - January 05, 2017; Revision- February 03, 2017; Accepted - February 16, 2017

Available Online - February 28, 2017

DOI: http://dx.doi.org/10.18006/2017.5(1).077.086

\section{KEYWORDS}

Heterosis

Combining ability

Hybrids

Gene action

\begin{abstract}
Heterosis and combining ability experiment in castor were carried in thirty nine crosses combinations along with their three females, thirteen males and one check hybrid $(\mathrm{GCH})$. Among hybrids, thirteen hybrids exhibited significant positive heterobeltiosis for seed yield, of these best three heterotic hybrids in order were SKP $84 \times$ PCS 124 (112.85 per cent) followed by SKP $84 \times$ JI 244 (108.67 per cent) and Geeta $\times$ JI 379 (94.07 per cent). Mean squares due to females, males and females $\times$ males were significant for all the traits indicating involvement of both additive and non-additive genetic components for most of the traits. On the basis of performance, heterotic response, combining ability estimates, nature of gene action for seed yield per plant and its attributing traits, hybrid Geeta $\times$ JI 379 was found superior over the rest hybrids. Several other hybrids had significant heterosis over the standard check in desired direction for days to 50 per cent flowering (30), days to 50 per cent maturity of primary spike (7), plant height (25), number of nodes up to primary spike (28), length of primary spike (18), number of capsules on primary spike (10), number of effective branches per plant (5), total number of branches per plant (7), 100-seed weight (4) and oil content (17).
\end{abstract}

* Corresponding author

E-mail: agrilstar25@gmail.com (A. S. Patil)

Peer review under responsibility of Journal of Experimental Biology and Agricultural Sciences.

Production and Hosting by Horizon Publisher India [HPI] (http://www.horizonpublisherindia.in/).

All rights reserved.
All the article published by Journal of Experimental Biology and Agricultural Sciences is licensed under a Creative Commons Attribution-NonCommercial 4.0 International License Based on a work at www.jebas.org.

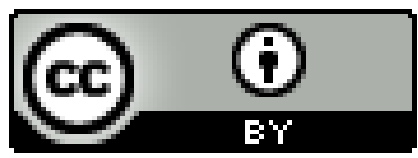




\section{Introduction}

Castor (Ricinus communis L.) appertains to family Euphorbiaceae. The castor have $2 n=20$ chromosome numbers and it is greatly cross-pollinated up to the level of 50 percent. Castor is native to India, Southeastern Mediterranean Basin and Eastern Africa but is prevalent throughout tropical regions. Castor is cultivated in tropical, sub-tropical and temperate regions of the world. It is grown in about 30 diverse countries on saleable scale, among these India, Brazil, China, Russia, Thailand and Philippines are the most vital castor growing countries. India is world leader in area, production and productivity with 10.4 lakh ha, 17.33 lakh tones and 1666.3 $\mathrm{kg} / \mathrm{ha}$, respectively during the year 2014 (FAOSTAT 2014). The seeds of castor contain about 40 to 60 per cent oil that is rich in triglycerides, principally ricinolein (Clans, 1959). Castor oil has great industrial value as it is used for the makeup of soaps, refined and perfumed hair oil, printing inks, varnishes, synthetic resins, carbon paper, lubricant, ointments, cosmetics and processed leather. The seed yield in castor is directly or indirectly influenced by several factors, out of which sex expression i.e., percent pistillate whorls is very important (Aher et al., 2015).

Heterosis is proved phenomenon and important genetic tool in increasing the yield of cross pollinated species in general and castor in particular. With the availability of 100 per cent pistillate lines in castor, exploitation of hybrid vigour on commercial scale has become feasible and economical (Gopani et al.,1968). The per se performance of parental lines provides clues, however, reliable information on magnitude of heterosis and combining ability of parent for yield and its component traits involved in the inheritance in different traits are of more helpful in selecting appropriate parents and desirable cross combinations.

Similarly, information on type of generation for different trait is prime importance in formulating appropriate breeding program for the improvement of seed yield and its components (Dangaria et al., 1987). Different mating designs have been used by different workers as an aid in the choice of parents and to comprehend their genetic worth. Various researchers reported heterosis in few agronomic traits in Castor crosses (Ramesh et al., 2013; Aher et al., 2015; Patel et al., 2015; Sapovadiya et al., 2015. Line $\times$ Tester analysis suggested by Kempthrone (1957) to elucidate nature of gene action and combining ability among parents for different several traits.

This technique is widely used for screening large number of lines and for identifying the best combination. Similarly, knowledge about nature of gene action governing the expression of various traits helps in breeding strategies to be adopted. Therefore, present investigation was carried out with objectives to estimate the magnitude of heterosis for seed yield and its component traits and characterize the superior parents and hybrids for commercial exploitation.

\section{Materials and Methods}

The present investigation was conducted during kharif 2009-11 at Regional Research Station, Anand Agricultural University, Anand. The soil of experimental site is sandy loam, alluvial in origin, deep, well drained and had fairly good moisture holding capacity. The experimental material was obtained from the Main Oilseeds Research Station, Junagadh Agricultural University (JAU), Junagadh, India. The details of the genotypes are given in Table 1. Three lines and thirteen testers were crossed using line $\times$ tester mating design to prepare thirty-nine hybrids during kharif 2009-2010. Thus, the experimental material consisted of 56 entries, three lines, thirteen testers and resultant thirty nine hybrids were evaluated along with one standard hybrid (GCH 7) as check. The racemes in female parents were bagged before opening of the flower. In the male parents, all opened flowers in the spike were clipped off prior to bagging to obtain uncontaminated pollen grains for pollination. At the time when stigma becomes receptive, collected pollen grains from desired male parents were dusted over the stigma of female parents. After pollination, female parent spikes were bagged and labeled. The dusting of pollens was repeated for three to four times to ensure sufficient seed setting on spike of female parents. At the same time pistillate lines were sibbed and male parents were selfed so as to get sufficient seed for experiment. All the seeds of crosses, sibbed pistillate lines and selfed inbred lines were harvested separately, cleaned and stored properly.

The complete set of fifty six entries was sown in a randomized complete block design (RCBD) with three replications during kharif, 2010-11. A single row of 6.0 meter length was assigned to each genotype with 10 dibbles having $60 \mathrm{~cm}$ intra row spacing and $120 \mathrm{~cm}$ inter row spacing. All recommended agronomic practices (dose of NPK (40:40:20 N: P2O5: K2O $\mathrm{Kg} / \mathrm{ha}$ ) and plant protection (Sprayed Carbaryl @ $0.2 \%$ for the control of semi-looper pest) measures were followed for raising normal crop. The observations were recorded on five randomly selected plants for eleven traits viz., days to 50 per cent flowering, days to maturity, number of nodes up to primary spike, plant height $(\mathrm{cm})$ up to primary spike, total number of branches per plant, length of primary spike $(\mathrm{cm})$, number of capsules on primary spike, number of effective branches per plant, seed yield per plant $(\mathrm{g}), 100$ seed weight (g) and oil content $(\%)$. Per cent oil content in castor seed was determined by using Nuclear Magnetic Resonance (NMRBRUKER make) (FT-NMR Spectrometer, 2001). The observations for days to 50 per cent flowering and maturity were recorded on plot basis. The replication wise mean values of each genotype for various traits were used for statistical analysis.

Analysis of variance (ANOVA) technique recommended by Panse \& Sukhatme (1969) was used to test the differences between the genotypes for all the traits. 
Table 1 Parental lines used in present study along with source of collection.

\begin{tabular}{|c|c|c|c|}
\hline Sr. No. & Genotypes & Pedigree & Sources \\
\hline \multicolumn{4}{|c|}{ Lines (Females) } \\
\hline 1. & VP-1 & $(\mathrm{JP} 5 \times 26006) \mathrm{F}_{2} \times(\mathrm{TSP}-10-\mathrm{R} \times \mathrm{JI} 15) \mathrm{F}_{2}$ & S.K.Nagar, Gujarat \\
\hline 2. & SKP 84 & SKP-1 $\times$ VP-1 & S.K.Nagar, Gujarat \\
\hline 3 & Geeta & Selection from $48-1$ & S.K.Nagar, Gujarat \\
\hline \multicolumn{4}{|c|}{ Testers (Males) } \\
\hline 4 & JI 321 & & Junagadh, Gujarat \\
\hline 5 & JI 342 & & Junagadh, Gujarat \\
\hline 6 & JI 273 & $(\mathrm{JP} 65 \times \mathrm{JI} 88) \times 48-1$ & Junagadh, Gujarat \\
\hline 7 & SKI 147 & VP $1 \times$ SH 63 & S.K.Nagar, Gujarat \\
\hline 8 & SKI 215 & $(\mathrm{SKI} 8 \mathrm{~A} \times \mathrm{SA} 2) \mathrm{F}_{10}$ & S.K.Nagar, Gujarat \\
\hline 9 & SKI 270 & Selection from SKI 80 & S.K.Nagar, Gujarat \\
\hline 10 & JI 379 & $\mathrm{~F}_{9} \mathrm{~S}(\mathrm{JP}-78 \times \mathrm{JI} 244)$ & Junagadh, Gujarat \\
\hline 11 & $\mathrm{SH} 41$ & $(\mathrm{CO} 1 \times 279) \times 413 \mathrm{~A}$ & S.K.Nagar, Gujarat \\
\hline 12 & $48-1$ & $\mathrm{MD} \times \mathrm{HO}$ & DOR, Hyderabad \\
\hline 13 & GC 2 & $279 \times 413 \mathrm{~A}$ & S.K.Nagar, Gujarat \\
\hline 14 & DSC 106 & & DOR, Hyderabad \\
\hline 15 & JI 244 & VP $1 \times \mathrm{SH} 42$ & Junagadh, Gujarat \\
\hline 16 & PCS 124 & PPL $4 \times 48-1$ & DOR, Hyderabad \\
\hline \multicolumn{4}{|c|}{ Standard hybrid } \\
\hline 17. & GCH-7 & SKP $84 \times$ SKI 215 & S.K.Nagar, Gujarat \\
\hline
\end{tabular}

Heterosis was estimated in terms of two parameters heterobeltiosis (expressed over better parent value) and standard heterosis (expressed over standard check hybrid GCH 7). Heterobeltiosis and standard heterosis are measured in term of percentage as proportion of deviation of hybrid from its superior parent and standard check hybrid GCH 7, respectively, as the formulae given by Singh \& Chaudhary (1985). Test of significance for heterosis was done by calculated the " $\mathrm{t}$ " value using standard error. The variation amongst the hybrids was further partitioned into sources contributed to general combining ability (gca) and specific combining ability (sca) components (Kempthorne, 1957). The classification of parents with respect to general combining ability (gca) was performed on basis of their test of significance, degree and direction of magnitude of trait values, respectively. The statistical analysis was performed by SAS 9.4 software (SAS, 2004). To demonstrate gene actions and magnitude of heterosis in angle and distance data Polar Plot 2 add-in excel 2003 used.

\section{Results and Discussion}

1.1 Analysis of variance for experimental design

The analysis of variance was performed to test the difference amongst parents and hybrids for eleven traits (Table 2).The results discovered that the mean squares due to genotypes were significant for all the traits in the study. The mean squares due to genotypes were further partitioned into parents, hybrids, parent's $v s$. hybrids and check vs. hybrids. The parents and hybrids differ significantly for all the traits. This indicates considerable genetic variability for all the traits among the parents and hybrids. ANOVA further revealed that hybrids differed significantly for all the traits. The mean squares due to parent's $v s$. hybrids were significant for all the traits, except days to fifty per cent flowering and oil content thereby suggesting possibility of heterotic effects for these traits (Table 2).

\subsection{Magnitude of heterosis}

The extent of heterosis over better parent and standard check, $(\mathrm{GCH} 7)$ for all eleven traits is presented in Figure 1. For days to 50 per cent flowering, days to 50 per cent maturity of primary spike, number of nodes up to primary spike and plant height, the small scoring parent was considered as superior parent for estimation of heterobeltiosis. For early flowering, significantly highest heterobeltiosis was observed in the cross VP $1 \times$ SKI 270 (-24.82 per cent), whereas, best hybrid which exhibited significant negative heterosis over GCH 7 was VP1 $\times$ SKI 270 (-35.76 per cent). VP $1 \times$ SKI 147 (-13.07 per cent) manifested significantly the highest standard heterosis for days to 50 per cent maturity of primary spike. For the plant height, Geeta $\times 48-1$ ( -45.61 per cent) was the best for heterobeltiosis while VP $1 \times$ PCS 124 (-48.92 per cent) was the best for standard heterosis.

Also, for number of nodes up to primary spike the most excellent cross combinations were VP $1 \times$ PCS 124 and SKP $84 \times \mathrm{SH} 41$ (-25.00 per cent). Length of primary spike is one of the important traits as it has greater contribution towards seed yield. 
The perusal of data revealed that the best hybrid exhibiting significant positive heterobeltiosis was Geeta $\times$ PCS 124 (54.12 per cent) whereas; cross SKP $84 \times$ SKI 147 (36.68 per cent) recorded maximum significant positive standard heterosis. Geeta $\times$ JI 379 depicted maximum significant positive heterobeltiosis (68.97 per cent) and standard heterosis (26.57 per cent) for number of capsules on the primary spike, The cross SKP $84 \times$ JI273 (90.00 per cent) depicted foremost significant positive heterobeltiosis for number of effective branches per plant. Among the hybrids evaluated, the maximum significant standard heterosis exhibited by Geeta $\times$ SKI 215 (26.67 per cent). The cross SKP $84 \times$ SKI 147 (45.95 per cent) depicted highest significant positive heterobeltiosis for total number of branches per plant. As regards to standard heterosis, cross SKP $84 \times$ JI 244 (14.81 per cent) was found significantly superior over GCH 7 for this trait.

The cross VP $1 \times$ JI 321 (38.43 per cent) was the best combination over better parent and VP $1 \times$ JI 321 (9.47 per cent) over standard check for 100 seed weight. Seed yield per plant is very important attribute to improve by evolving new high yielding hybrids. The SKP $84 \times$ PCS 124 (112.85 per cent) was the best hybrid on the basis of maximum significant heterobeltiosis for this trait. Result revealed narrow range of heterobeltiosis and standard heterosis for oil content trait. It was noticed that the cross VP $1 \times$ JI 244 (5.47 per cent) was significantly superior over better parent for oil content and the cross Geeta $\times$ DSC 106 (6.11 per cent) was significantly superior over standard check for oil content.

Commercial exploitation of heterosis in castor is considered as one of the major step forward in the field of castor improvement. Castor is highly cross pollinated crop and with the availability of 100 per cent pistillate lines, heterosis has been successfully exploited in castor and first castor hybrid GCH 3 (TSP-10 R $\times \mathrm{J}$ 1) was released for general cultivation in Gujarat as early in 1968 (Gopani et al. 1968).

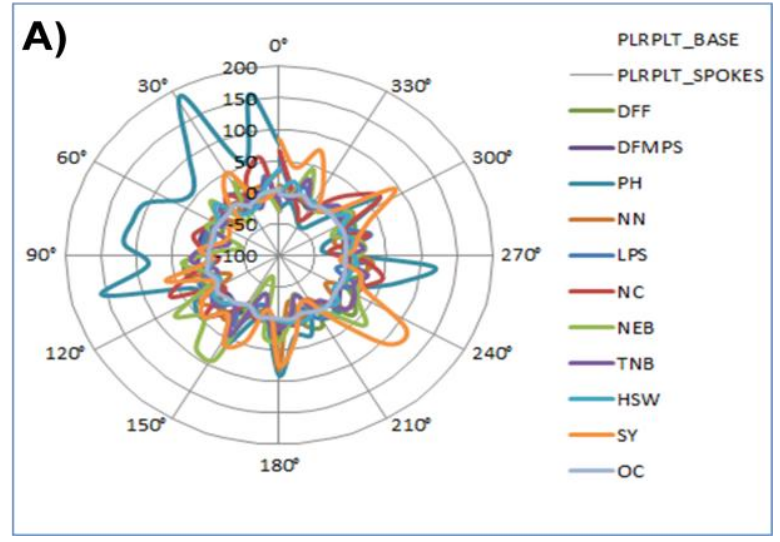

In present investigation, the heterosis was measured over the better parent and standard check hybrid GCH 7 to search out the best combination of parents giving high degree of useful heterosis and characterization of parents for future use in breeding programme.

Good number of hybrids had significant desired heterosis over the better parent as well as standard check hybrids for various traits in present study (Figure 1). Thirteen hybrids manifested significant positive heterosis over better parents for seed yield per plant with the highest magnitude was recorded by the hybrid SKP $84 \times$ PCS 124 (112.85 per cent). Many hybrids exhibited significant heterosis over better parent in desirable direction for different component traits such as days to 50 per cent flowering (13), days to 50 per cent maturity of primary spike (2), plant height (8), number of nodes up to main spike (15), length of primary spike (19), number of capsules on primary spike (22), number of effective branches per plant (25), total number of branches per plant (17), 100-seed weight (20) and oil content (9). It was observed that hybrids showing high heterobeltiosis for seed yield per plant in general also manifested heterotic effects for its contributing traits like length of main spike, number of capsules on main raceme number of effective branches per plant and 100 -seed weight. This study thus substantiates the findings of Purohit et al. (2010); Ramesh et al. (2013); Aher et al. (2015); Patel et al. (2015) and Sapovadiya et al. (2015).

Enhancement in yield is the most central objectives, so the superiority of hybrids over best cultivated hybrid is essential for increasing its commercial value. In present study, recently released hybrid GCH 7 was used as standard check. The hybrid Geeta $\times$ JI 379 had highest standard heterosis $(25.62$ per cent $)$ over the best check GCH 7 but Geeta $\times$ JI 379 secured third position in respect of significant positive heterosis over better parent ( 94.07 per cent) and also had significant positive desired sca effects (77.76) for seed yield per plant.

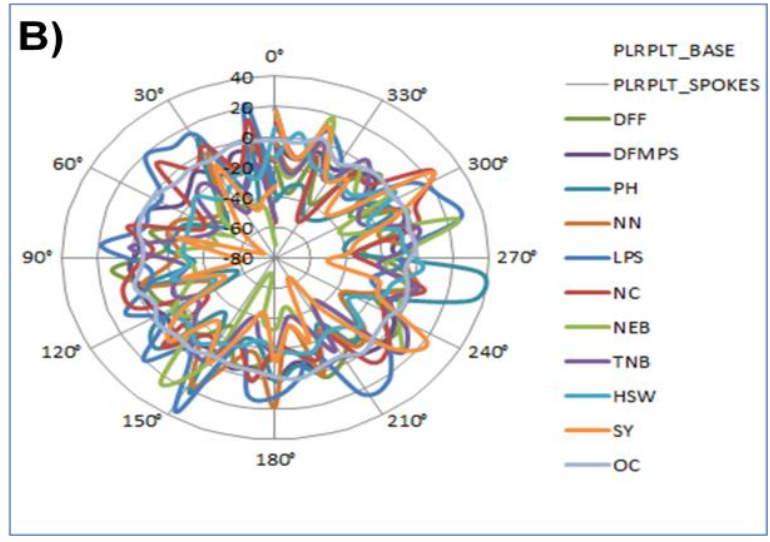

Figure 1 Magnitude of A) Heterobeltiosis (HB) and B) Standard heterosis (SH).

[DFF: Days to 50 per cent flowering, DFMPS: Days to 50 per cent maturity of primary spike, PH: Plant height (cm), NN: Number of nodes up to primary spike, LPS: Length of primary spike $(\mathrm{cm}), N C$ : Number of capsules on primary spike, NEB: Number of effective branches per plant, TNB: Total number of branches per plant, HSW: 100 seed weight (g), SY: Seed yield per plant (g), OC: Oil content $(\%)]$. 
A perusal of Figure 1 revealed that several hybrids had significant heterosis over the standard check in desired direction for days to 50 per cent flowering (30), days to 50 per cent maturity of primary spike (7), plant height (25), number of nodes up to primary spike (28), length of primary spike (18), number of capsules on primary spike (10), number of effective branches per plant (5), total number of branches per plant (7), 100 -seed weight (4) and oil content (17).

As observed in the present investigation, several workers have also reported the presence of considerable degree of heterosis for seed yield per plant (Patel \& Pathak 2006; Gauri Shankar et al., 2010; Kavani et al., 2010; Patel et al., 2010; Purohit et al., 2010), for number of effective branches per plant, plant height, number of nodes up to primary spike (Thakker et al., 2005); length of primary spike; number of capsules on the primary spike, total number of branches plant and 100-seed weight (Thakker et al., 2005) in castor. Relatively low heterosis for days to 50 per cent flowering and maturity as observed in present investigation was also reported by Thakker et al. (2005); Patel et al. (2008a), Patel et al. (2008 b) and Purohit et al. (2010).

The utility of heterosis breeding approach lies in the identification of most heterotic and useful cross combinations in order to develop well adapted commercial hybrid. Out of 39 tested hybrids, the eight promising hybrids which out yielded GCH 7 were identified in respect of seed yield per plant. Among eight promising hybrids, female parents SKP 84 and Geeta were involved in 4 and 3 hybrids, respectively. Whereas, inbred line PCS 124 was involved in 2 hybrids. Hence, females SKP 84 and Geeta and male PCS 124 found good for heterotic expression in their hybrids than other parents.

It was further revealed that the best performing hybrid Geeta $\times$ JI 379 had significant and positive heterobeltiosis (25.62 per cent) and heterobeltiosis ( 94.07 per cent) and also exhibited significant positive sca effects (77.76 per cent) for seed yield per plant. All eight promising hybrids, depicted significant and positive sca effects for seed yield per plant, hence indicated involvement of non additive gene action in the heterotic response. This was also confirmed by the ratio of variance components for seed yield per plant in the analysis of variance for combining ability (Table 3 ). The best three hybrids identified on the basis of performance viz., Geeta $\times$ JI 379, SKP $84 \times$ PCS 124 and Geeta $\times$ PCS 124 also had significant positive heterosis over GCH 7 for majority of the yield contributing traits viz., length of primary spike, number of capsules on main spike, number of effective branches per plant and 100 seed weight.

This emphasized that high degree of heterosis for seed yield might be attributed to the heterosis for these component traits. Graffius (1959) have suggested that there cannot be any gene system for seed yield per se, as yield is an end product of the multiplicative action and interaction of several yield components. Similar findings have been reported by Purohit et al. (2010).
It was experienced that most of the promising hybrids exhibited significant negative standard heterosis for the trait days to 50 per cent flowering; thereby suggesting that high yield in hybrids can also be achieved along with early maturity. On the whole, considerable heterobeltiosis and standard heterosis observed for seed yield and other associated traits suggested the presence of large genetic diversity among the males and the females and also the unidirectional distribution of allelic constitution contributing towards desirable heterosis, whereas, low magnitude of desirable heterosis and heterobeltiosis for some of the traits viz., oil content and 100seed weight indicated the narrow genetic base among the males and the females and also the ambi-directional distribution of allelic constitution contributing towards undesirable heterosis or may be due to mutual cancellation of effects of dominant alleles present in the material (Sharma, 1994).

\subsection{Analysis of combining ability}

Analysis of variance for combining ability was done for eleven traits and presented in Table 3 . The variation among hybrids was partitioned in to portions attributable to females, males and female $\times$ males and error sources. ANOVA for combining ability revealed that mean squares due to females (lines) and to males (testers) were significant for all the traits studied. The variance due to hybrids was also significant for all the traits studied. The variance due to female's $\times$ male's interaction was also highly significant for all the traits except days to 50 per cent maturity of primary spike. This reflected the importance of non-additive gene action in the inheritance of various traits. A comparison of variances due to males and females indicated that the females showed higher variability for the traits like days to 50 per cent flowering, number of nodes up to primary spike, number of effective branches per plant, total number of branches per plant, 100 seed weight and seed yield per plant while males had higher value of variance for the traits like days 50 per cent maturity of primary spike, plant height, length of primary spike, number of capsules on primary spike and oil content. A perusal of variance ratio suggested preponderance of non additive gene action for all the traits.

In a crop improvement program, much of the success depends upon isolation of valuable genes combinations as determined in the form of lines with high combining ability. The genetic components analysis along with combining ability analysis is a powerful tool to discriminate good as well as poor combiners, and to choose appropriate parental material in breeding program. The general combining ability is an average performance of a parental line in a series of hybrid combinations, and can be recognized as a measure of additivity of genes; whereas, specific combining ability is deviation from the expected performance of specific hybrid combination on the basis of average performance of parents involved, and can be regarded as a measure of non-additive gene action resulted from both intra-allelic and inter-allelic gene interactions (Sprague \& Tatum, 1942). 
Table 2 Analysis of variance (mean squares) for yield and its components.

\begin{tabular}{|c|c|c|c|c|c|c|c|c|c|c|c|c|}
\hline Source & D.F. & DFF & DFMPS & PH (cm) & NN & LPS (cm) & NC & NEB & TNB & HSW (g) & SY (g) & $\mathrm{OC}(\%)$ \\
\hline Replications & 2 & 12.87 & 18.37 & 8.81 & 1.73 & 7.12 & 10.87 & 0.92 & 1.86 & 1.76 & 606.50 & 0.92 \\
\hline Genotypes & 55 & $151.131 * *$ & $173.01 * *$ & $1228.11 * *$ & $18.35 * *$ & $394.17 * *$ & $772.50 * *$ & $33.42 * *$ & $23.55^{\text {*** }}$ & $37.76^{* *}$ & $11057.16^{* *}$ & $5.65 * *$ \\
\hline Parents & 15 & $142.74 * *$ & $291.28 * *$ & $1989.63 * *$ & $27.28 * *$ & $302.74 * *$ & $763.28 * *$ & $32.43 * *$ & $26.70^{* * *}$ & $36.86^{* * *}$ & $4513.42 * *$ & $12.25^{* * *}$ \\
\hline Lines & 2 & 254.11 & $320.33 * *$ & 2629.75 & $13.00^{*}$ & $234.16^{* *}$ & 194.77 & 24.11 & 10.77 & $33.78 * *$ & 1628.44 & 37.81 \\
\hline Testers & 12 & 70.91 & $306.4 * *$ & 1840.25 & $31.71 * *$ & $339.38 * *$ & 805.39 & $35.24 *$ & 29.76 & $40.40 * *$ & $5259.37 * *$ & 7.26 \\
\hline Lines $v s$ Testers & 1 & $782.10 * *$ & 51.00 & $2502.03 *$ & $2.76^{* *}$ & 0.14 & $1395.01 * *$ & $15.43^{* * *}$ & $21.79 * *$ & 0.59 & 1331.90 & $21.05^{* *}$ \\
\hline Hybrids & 38 & $159.17 * *$ & $127.33 * *$ & $948.94 * *$ & $15.45 * *$ & $367.51 * *$ & $659.50 * *$ & $30.99 * *$ & $21.64 * *$ & $31.85 * *$ & $11262.75^{* * *}$ & $3.31 * *$ \\
\hline Parents $v s$ hybrids & 1 & 1.08 & $289.12 * *$ & $1281.75 * *$ & $6.59 * *$ & $3170.37 * *$ & $5767.26^{* *}$ & $143.06 * *$ & $47.95^{* *}$ & $235.39 * *$ & $97220.00^{* *}$ & 0.58 \\
\hline Check vs hybrids & 1 & $122.44 * *$ & 33.67 & $482.29 * *$ & $7.55 * *$ & 41.77 & 63.23 & $20.66^{* *}$ & $18.59^{* * *}$ & $56.37 * *$ & $9293.59 * *$ & 0.30 \\
\hline Error & 110 & 4.46 & 19.75 & 20.14 & 0.64 & 12.57 & 30.34 & 1.38 & 2.43 & 0.74 & 513.00 & 0.46 \\
\hline
\end{tabular}

$[*$ ** Significant at $5 \%$ and $1 \%$ levels of probability, respectively. DFF: Days to 50 per cent flowering, DFMPS: Days to 50 per cent maturity of primary spike, PH: Plant height (cm), NN: Number of nodes up to primary spike, LPS: Length of primary spike (cm), NC: Number of capsules on primary spike, NEB: Number of effective branches per plant, TNB: Total number of branches per plant, HSW: 100 seed weight ( $g$ ), SY: Seed yield per plant ( $g$ ), OC: Oil content $(\%)]$

Table 3 Analysis of variance (mean squares) and variance estimates of combining ability for yield and its components.

\begin{tabular}{|c|c|c|c|c|c|c|c|c|c|c|c|c|}
\hline Source & D.F. & DFF & DFMPS & PH (cm) & NN & LPS (cm) & NC & NEB & TNB & HSW (g) & SY (g) & $\mathrm{OC}(\%)$ \\
\hline Replications & 2 & 12.47 & 11.93 & 58.78 & 1.85 & 1.49 & 31.28 & 1.47 & 2.88 & 1.38 & 392.47 & 0.33 \\
\hline Hybrids & 38 & 159.17 & 127.33 & 948.94 & 15.42 & 367.51 & 659.50 & 30.99 & 21.64 & 31.85 & 11262.75 & 3.31 \\
\hline Lines & 2 & $456.65 * *$ & $296.52 * *$ & $1542.43 * *$ & $44.93 * *$ & $312.29 * *$ & $24.87 * *$ & $192.72 * *$ & 73.49 ** & $183.94 * *$ & $60281.40 * *$ & $0.80 * *$ \\
\hline Testers & 12 & $168.59 * *$ & $159.78 * *$ & $1095.58 * *$ & $17.30 * *$ & $483.78 * *$ & $1081.83 * *$ & $12.58 * *$ & $15.43^{* *}$ & $36.07 * *$ & $10325.06 * *$ & $5.10 * *$ \\
\hline Line vs tester & 24 & $129.66^{* *}$ & 97.00 & $826.16 * *$ & $12.07 * *$ & $313.98 * *$ & $501.23 * *$ & $26.71 * *$ & $20.43^{* *}$ & $17.06^{* *}$ & $7646.69^{* *}$ & $2.63 * *$ \\
\hline Error & 76 & 4.99 & 13.15 & 17.17 & 0.61 & 10.02 & 33.12 & 1.36 & 2.27 & 0.89 & 556.66 & 0.40 \\
\hline \multicolumn{13}{|l|}{ ESTIMATES } \\
\hline$\sigma^{2} L$ & & 8.38 & 5.12 & 18.37 & 0.84 & -0.04 & -12.21 & 4.26 & 1.36 & 4.28 & 1349.61 & -0.05 \\
\hline$\sigma^{2} \mathrm{~T}$ & & 4.33 & 6.98 & 29.94 & 0.58 & 18.87 & 64.51 & -1.57 & -0.56 & 2.11 & 297.60 & 0.27 \\
\hline$\sigma^{2}$ gca $\left(\sum \mathrm{gi}^{2}\right)$ & & 7.62 & 5.46 & 20.53 & 0.79 & 3.50 & 2.17 & 3.16 & 1.00 & 3.87 & 1152.35 & 0.013 \\
\hline$\sigma^{2} \mathrm{sca}\left(\sum \sum \mathrm{sij}^{2}\right)$ & & 41.56 & 27.96 & 269.67 & 3.82 & 101.32 & 156.03 & 8.45 & 6.05 & 5.39 & 2364.35 & 0.74 \\
\hline$\Sigma^{2} \mathrm{~A}$ & & 30.49 & 21.86 & 82.14 & 3.17 & 14.01 & 8.69 & 12.66 & 4.01 & 15.49 & 4609.42 & 0.05 \\
\hline$\Sigma^{2} \mathrm{D}$ & & 166.23 & 111.80 & 1078.66 & 15.27 & 405.28 & 624.14 & 33.80 & 24.21 & 21.56 & 9453.37 & 2.98 \\
\hline$\left[\sigma^{2} \mathrm{D} / \sigma^{2} \mathrm{~A}\right]^{0.5}$ & & 2.33 & 2.26 & 3.62 & 2.19 & 5.37 & 8.47 & 1.63 & 2.45 & 1.17 & 1.43 & 7.72 \\
\hline
\end{tabular}

$[*, * *$ Significant at $5 \%$ and $1 \%$ levels of probability, respectively. DFF: Days to 50 per cent flowering, DFMPS: Days to 50 per cent maturity of primary spike, PH: Plant height (cm), NN: Number of nodes up to primary spike, LPS: Length of primary spike (cm), NC: Number of capsules on primary spike, NEB: Number of effective branches per plant, TNB: Total number of branches per plant, HSW: 100 seed weight (g), SY: Seed yield per plant (g), OC: Oil content (\%)]. 

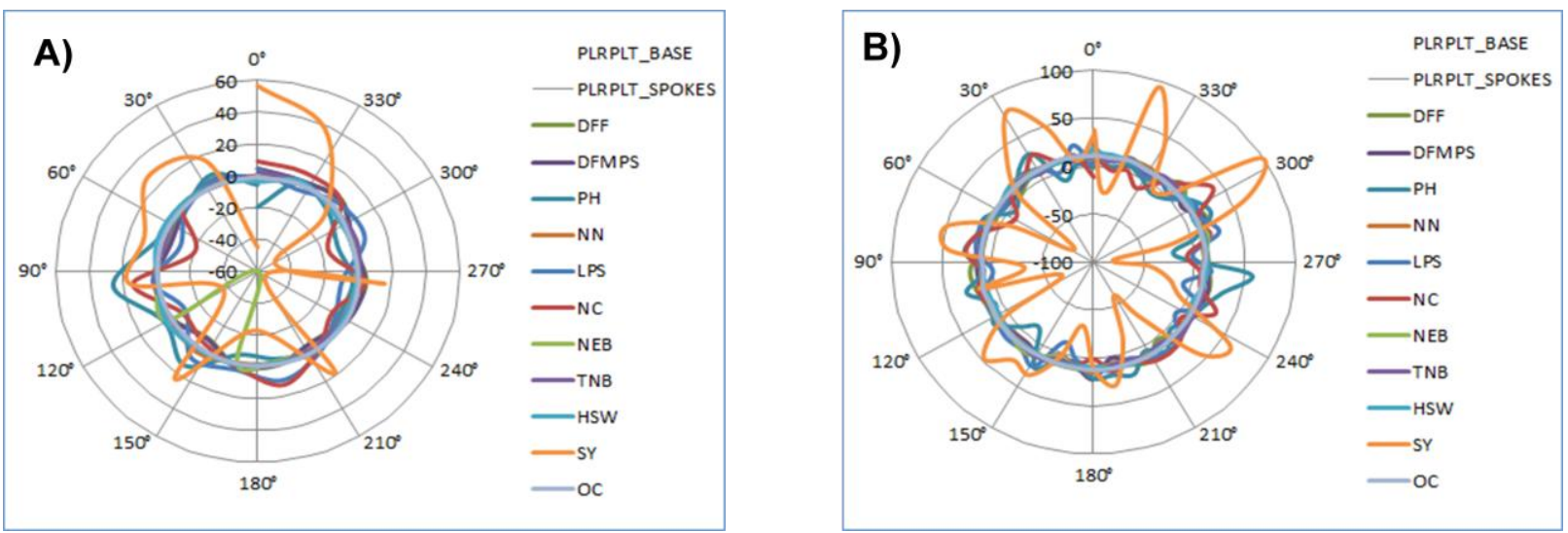

Figure 2 Estimates of A) general combining ability effects (gca) B) specific combining ability effects (sca) for yield and its components.

[DFF: Days to 50 per cent flowering, DFMPS: Days to 50 per cent maturity of primary spike, PH: Plant height (cm), NN: Number of nodes up to primary spike, LPS: Length of primary spike $(\mathrm{cm}), \mathrm{NC}$ : Number of capsules on primary spike, NEB: Number of effective branches per plant, TNB: Total number of branches per plant, HSW: 100 seed weight (g), SY: Seed yield per plant (g), OC: Oil content $(\%)]$.

Analysis of variance for combining ability (Table 3) revealed that both additive and non-additive genetic variances were important in the inheritance of various traits as evident from significance of females, males and female's $\times$ male's interaction for all the eleven traits. These results are in accordance with those obtained by Purohit et al. (2010); Ramesh et al. (2013); Aher et al. (2015); Patel et al. (2015) and Sapovadiya et al. (2015).The estimates of components of variance and their ratio $\left(\sigma^{2}\right.$ gca/ $\sigma^{2}$ sca $)$ indicated predominant role of non-additive gene action in controlling expression of all the traits studied. As observed in the present study, the predominant role of non-additive gene action was also observed by Chandramohan et al. (2006); Patel et al. (2008a, 2008b); Sridhar et al. (2008); Patel et al. (2010);Venkata Raman et al. (2010) for seed yield per plant, Patel et al. (2008a) for days to 50 per cent flowering, Patel et al. (2008a) for days to 50 per cent maturity, Patel et al. (2008a) and Patel et al. (2008b) for plant height up to primary spike, Patel et al. (2008b) for number of nodes up to primary spike, Patel \& Pathak (2006) for length of primary spike, Patel et al. (2008b) for number of capsules on primary spike, Patel et al. (2008a \& 2008b) for number of effective branches per plant, Patel et al. (2008a, 2008b) for 100 seed weight and Chandramohan et al. (2006); Sridhar et al. (2008); Purohit et al. (2010); Ramesh et al. (2013); Aher et al. (2015); Patel et al. (2015) and Sapovadiya et al. (2015) for oil content.

Looking to the significance of both types of gene actions in the expression of different traits, it is suggested that bi-parental mating with reciprocal recurrent selection should be employed so that additive as well as non-additive gene action could be exploited simultaneously for population improvement. However, in view of the preponderance of non-additive gene action and high heterosis observed for seed yield and yield attributing traits, it is suggested that heterosis breeding can profitably be used for exploitation of hybrid vigour in castor on commercial scale.

1.4 Estimates of general and specific combining ability effects

Estimates of general combining ability (GCA) effects of parents and specific combining ability (SCA) effects of hybrids for eleven traits are presented in Figure $2 \mathrm{~A}$ and $\mathrm{B}$, respectively. Early flowering is desirable as the castor is perennial in habit. Hence, early flowering genotype with negative significant GCA effects is preferred for this trait.

The female parent, VP 1 was good combiner for four traits (DFF, DFMPS, PH and NN), SKP 84 was for three traits (LPS, NE and SY) and Geeta was for seven traits (DFMPS, PH, NEB.TNB, HSW, SY and OC). While male parent, JI 321 was good combiner for five traits (DFF, DFMPS, NN, HS and OC), JI 342 for four traits (LPS, NC, TNB and SY), JI 273 for two traits (NEB and HSW), SKI 147 for five traits (DFF, DFMPS, LPS, NEB and SY), SKI 215 for three traits (PH, NN and LPS), SKI 270 for four traits (PH, NN, LPS and NC), JI 379 for six traits (DFF, DFMPS, LPS, HSW, SY and OC), SH-41 for three traits (PH, NN and OC), 48-1 for three traits ( $\mathrm{PH}, \mathrm{NC}$ and SY), GC 2 for six traits (DFF, PH, NN, LPS, NEB and TNB), DSC 106 for four traits (PH, LPS, NC and OC), JI 244 for five traits (NC, NEB, TNB, HSW and SY), PCS 124 for seven traits (PH, NN, LPS, NC, NEB, TNB and SY) (Figure 2 $\mathrm{A}$ and $\mathrm{B})$. 
Table 4 Summary of three best performing parents, best general combining parents and best performing hybrids along with their per cent heterosis over better parent and standard check hybrid (GCH 7) and sca effects

\begin{tabular}{|c|c|c|c|c|c|c|c|}
\hline \multirow[t]{2}{*}{ Traits } & \multirow[t]{2}{*}{ Rank } & \multirow{2}{*}{$\begin{array}{l}\text { Best performing } \\
\text { parents }\end{array}$} & \multirow{2}{*}{$\begin{array}{c}\text { Best general } \\
\text { combiners }\end{array}$} & \multirow[t]{2}{*}{ per se performance } & \multicolumn{2}{|c|}{ Heterosis over } & \multirow[t]{2}{*}{ Sca effects } \\
\hline & & & & & Better parent & GCH 7 & \\
\hline \multirow[t]{3}{*}{ DFF } & $1^{\mathrm{st}}$ & JI 379 & SKI 147 & VP $1 \times$ SKI 270 & $-24.82 * *$ & -35.76 & $-9.97 * *$ \\
\hline & $2^{\text {nd }}$ & JI 244 & JI 379 & VP $1 \times$ SKI 147 & $-20.74 * *$ & -35.15 & -0.97 \\
\hline & $3^{\text {rd }}$ & JI 273 & JI 321 & VP $\times$ JI 321 & $-18.12 * *$ & -31.52 & $-3.31 * *$ \\
\hline \multirow[t]{3}{*}{ DFMPS } & $1^{\mathrm{st}}$ & JI 379 & SKI 147 & VP $1 \times$ SKI 147 & -3.55 & $-13.07 * *$ & $-3.57 * *$ \\
\hline & $2^{\text {nd }}$ & SKI 147 & JI 379 & VP $1 \times$ JI 379 & 4.76 & $-12.00 * *$ & $-5.13 * *$ \\
\hline & $3^{\text {rd }}$ & VP 1 & JI 321 & $\mathrm{VP} 1 \times \mathrm{JI} 321$ & -4.35 & $-12.00 * *$ & $-5.24 * *$ \\
\hline \multirow[t]{3}{*}{$\mathrm{PH}(\mathrm{cm})$} & $1^{\mathrm{st}}$ & VP 1 & PCS 124 & $\mathrm{VP} 1 \times \mathrm{PCS} 124$ & $30.99^{* *}$ & $-48.92 * *$ & $-4.13 * *$ \\
\hline & $2^{\text {nd }}$ & JI 379 & GC 2 & Geeta $\times 48-1$ & $-45.61 * *$ & $-41.14 * *$ & $-7.75 * *$ \\
\hline & $3^{\text {rd }}$ & JI 273 & SKI 215 & Geeta $\times$ GC 2 & $-44.91 * *$ & $-40.28 * *$ & $-0.23 * *$ \\
\hline \multirow[t]{3}{*}{ NN } & $1^{\mathrm{st}}$ & JI 321 & PCS 124 & VP $1 \times$ PCS 124 & $-25.00 * *$ & $-33.33 * *$ & $-0.98 * *$ \\
\hline & $2^{\text {nd }}$ & JI 379 & VP 1 & $\mathrm{VP} 1 \times \mathrm{SKI} 270$ & $-17.78 * *$ & $-31.48^{* * *}$ & $-1.87 * *$ \\
\hline & $3^{\text {rd }}$ & JI 273 & SH-41 & SKP $84 \times$ PCS 124 & $-20.83 * *$ & $-29.63 * *$ & $-2.19 * *$ \\
\hline \multirow{3}{*}{ LPS $(\mathrm{cm})$} & $1^{\mathrm{st}}$ & SKI 270 & SKI 270 & SKP $84 \times$ SKI 147 & $30.06^{* *}$ & $36.68 * *$ & $11.54 * *$ \\
\hline & $2^{\text {nd }}$ & $\mathrm{GC} 2$ & SKI 147 & Geeta $\times$ SKI 215 & $33.24 * *$ & $28.91 * *$ & $15.73^{* * *}$ \\
\hline & $3^{\text {rd }}$ & SKI 147 & GC 2 & SKP $84 \times$ DSC 106 & $21.35^{* *}$ & $25.24 * *$ & $6.96^{* * *}$ \\
\hline \multirow{3}{*}{$\mathrm{NC}$} & $1^{\mathrm{st}}$ & DSC 106 & JI 342 & Geeta $\times$ JI 379 & $68.97 * *$ & $26.57 * *$ & $9.25 * *$ \\
\hline & $2^{\text {nd }}$ & SKI 270 & SKI 270 & VP $1 \times$ JI 342 & $56.85^{* * *}$ & $14.02^{* * *}$ & 2.14 \\
\hline & $3^{\text {rd }}$ & SKI 147 & PCS 124 & VP $1 \times$ SKI 270 & 1.32 & $13.65^{* * *}$ & 3.03 \\
\hline \multirow{3}{*}{ NEB } & $1^{\text {st }}$ & SKI 215 & Geeta & Geeta $\times$ SKI 215 & $11.76^{* *}$ & $26.67 * *$ & $4.74 * *$ \\
\hline & $2^{\text {nd }}$ & $48-1$ & PCS 124 & SKP $84 \times$ JI 273 & $90.00 * *$ & $26.67 * *$ & $4.79 * *$ \\
\hline & $3^{\text {rd }}$ & GC 2 & JI 273 & Geeta $\times$ DSC 106 & $45.95 * *$ & $20.00^{* * *}$ & $3.18^{* * *}$ \\
\hline \multirow{3}{*}{ TNB } & $1 \mathrm{st}$ & $48-1$ & PCS 124 & SKP $84 \times$ JI 244 & $26.53 * *$ & $14.81^{* * *}$ & $3.83 * *$ \\
\hline & 2nd & SKI 215 & GC 2 & SKP $84 \times$ PCS 124 & $25.00 * *$ & $11.11 * *$ & $2.27 * *$ \\
\hline & $3 \mathrm{rd}$ & JI 273 & Geeta & Geeta $\times$ DSC 106 & $26.67 * *$ & $5.56 * *$ & $2.88 * *$ \\
\hline \multirow{3}{*}{ HSW (g) } & $1 \mathrm{st}$ & JI 273 & JI 321 & $\mathrm{VP} 1 \times \mathrm{JI} 321$ & $38.43 * *$ & $9.47 * *$ & $6.51 * *$ \\
\hline & 2nd & SKI 147 & JI 273 & Geeta $\times$ JI 244 & $20.18 * *$ & $7.18 * *$ & $2.25 * *$ \\
\hline & $3 \mathrm{rd}$ & SKI 215 & JI 244 & Geeta $\times$ JI 273 & $8.26 * *$ & $6.62 * *$ & $1.41 * *$ \\
\hline \multirow{3}{*}{ SY (g) } & $1 \mathrm{st}$ & $48-1$ & PCS 124 & Geeta $\times$ JI 379 & $94.07 * *$ & 25.62 & $77.76 * *$ \\
\hline & 2nd & SKI 270 & JI 244 & SKP $84 \times$ PCS 124 & $112.85^{* *}$ & 23.02 & $45.07 * *$ \\
\hline & $3 \mathrm{rd}$ & JI 342 & Geeta & Geeta $\times$ PCS 124 & $84.89 * *$ & 19.68 & $23.76 * *$ \\
\hline \multirow{3}{*}{ OC (\%) } & $1 \mathrm{st}$ & SKI 147 & SH 41 & Geeta $\times$ DSC 106 & 0.94 & $6.11 * *$ & $1.39 * *$ \\
\hline & 2nd & Geeta & DSC 106 & VP $1 \times$ JI 244 & $5.47 * *$ & $4.54 * *$ & $1.39^{* *}$ \\
\hline & $3 \mathrm{rd}$ & $48-1$ & JI 321 & SKP $84 \times$ SH 41 & $1.62 * *$ & $4.41 * *$ & $0.60 *$ \\
\hline
\end{tabular}

[*,*, significant at $5 \%$ and $1 \%$ level of probability, respectively. DFF: Days to 50 per cent flowering, DFMPS: Days to 50 per cent maturity of primary spike, PH: Plant height (cm), NN: Number of nodes up to primary spike, LPS: Length of primary spike (cm), NC: Number of capsules on primary spike, NEB: Number of effective branches per plant, TNB: Total number of branches per plant, HSW: 100 seed weight (g), SY: Seed yield per plant (g), OC: Oil content $(\%)]$.

Similarly, among best five crosses for seed yield and component traits Geeta $\times$ JI 379 cross was good specific combiner for eight traits (DFF, DFMPS, PH, NN, LPS, NC and HSW), SKP $84 \times$ PCS 124 for four traits $(\mathrm{PH}, \mathrm{NN}$, NEB and TNB), Geeta $\times$ PCS 124 for five traits (DFF, DFMPS, PH, LPS and NC), Geeta $\times$ DSC 106 for seven traits (DFF, DFMPS, PH, NN, LPS, NEB and TNB), SKP $84 \times$ JI 244 for six traits (PH, NN, LPS, NC, NEB and TNB), SKP $84 \times \mathrm{JI}$ 342 for four traits (DFF, DFMPS, LPS and NC), SKP $84 \times$ SKI 147 for three traits( DFF, DFMPS and LPS) and Geeta $\times$ SKI 270 for four traits ( PH, LPS, NC and OC).
It was also recorded that the per se performance for different traits in general agreed with the GCA effects. However, this cannot be taken as a rule because parents or genotypes with high per se performance need not always be good general combiners. This could be attributed due to the intra and/or inter-allelic interaction of genes concerned with the trait modified by environmental factors (Dabholkar, 1999). In general, it was evident that parents who were good general combiners for seed yield per plant also were good combiners for most of its yield contributing traits. Use of parent viz., Geeta and PCS 124 would be more rewarding for boosting yield in castor. It was further noted that involvement of these 
parents had resulted into hybrids expressing useful heterosis for seed yield and various traits for majority of cases. The perusal of data on SCA effects (Figure $2 \mathrm{~B}$ ) revealed that none of the hybrid was consistently superior for all the traits. Out of 39 hybrids studied, 15 cross combinations exhibited significant positive SCA effects for seed yield per plant. The best three hybrids on the basis of significant positive SCA effects for seed yield per plant were Geeta $\times$ JI 379, Geeta $\times$ DSC 106 and VP $1 \times$ SKI 147 . These hybrids also exhibited significant positive SCA effects for majority of yield attributing traits viz., length of primary spike, number of capsules on primary spike, number of effective branches per plant and 100 seed weight

A perusal of Table 4 showed a good agreement between best general combining parents and best performing parents for several traits. This suggested that while selecting the parents for hybridization program, per se performance of parents should be given due consideration. Such parallel behavior of per se performance and general combining ability was also reported by Thakker et al. (2005) and Patel et al. (2008a, 2008b). Three best performing hybrids for various traits also had high heterotic response over better parent as well as standard check hybrid and high SCA effects in desirable direction.

Therefore, it can be concluded that per se performance of parents and hybrids agreed well with general combining ability effects of parents and heterotic response of hybrids, respectively. Thus, the potentiality of a strain to be used as a parent in hybridization, or a cross to be used as a commercial hybrid may be judged by comparing per se performance of parents and hybrids, along with combining ability effects of parents and heterotic response of hybrids. The crosses exhibiting higher per se performance, high heterosis and significant desirable SCA effects (Table 4) for various traits involved either good $\times$ good, good $\times$ average, good $\times$ poor, average $\times$ good, average $\times$ average, average $\times$ poor, poor $\times$ good and poor $\times$ average combining parents. Thus, cross exhibiting high sca effects did not always involve parents with high gca effects. It is suggested that inter-allelic interactions were also important for these traits.

The best three hybrids for seed yield per plant viz., Geeta $\times$ JI 379, SKP $84 \times$ PCS 124 and Geeta $\times$ PCS 124had significant positive SCA effects and high heterotic response over their better parent and standard check hybrid. High yielding hybrids had high SCA effects, high heterosis as well as high per se performance for most of its yield contributing traits. This appeared appropriate as yield being a complex trait depends on a number of its component traits. Good general combiners may not necessarily produce good specific combinations for different traits. In many cases, it was observed that at least one good general combining parent was involved in heterotic hybrid having desirable SCA effects. This suggested that information of SCA effects of parents should be considered along with SCA effects and per se performance of hybrid for predicting the value of any hybrid. It can be concluded from the above results that hybrid Geeta $\times$ JI 379 is the most promising and may be exploited in practical plant breeding program. However, before its utility on commercial scale, this hybrid should be evaluated critically at multiplications across the years to judge its superiority and stability in performance.

\section{Acknowledgements}

We are extremely grateful to Department of Agriculture, Botany and Regional Research Station, Anand Agricultural University, Anand for providing facility for this research study.

\section{Conflict of interest}

Authors would hereby like to declare that there is no conflict of interests that could possibly arise.

\section{References}

Aher AR, Patel KV, Patel MP, Patel JA (2015) Genetic analysis of seed yield and component traits over environments in castor (Ricinus communis L.). Electronic Journal of Plant Breeding 6: 141-149.

Clans ED (1959) Pharmacognasy. Lea and Febriger Philadelphia. Pp.179-181.

Chandramohan H, Reddy AV, Rao TN (2006) Combining ability in castor, Ricinus communis L. Journal of Oilseeds Research 23: 178-183.

Dabholkar AR (1999) Elements of Biometrical Genetics. Concept Publishing Company, New Delhi, Pp. 248.

Dangaria CJ, Dobaria KL, Fatteh UG, Patel VJ (1987) Heterosis and combining ability analysis in castor. Journal of Oilseeds Research 4: 46-53.

FAOSTAT (2014) htpp://faostat.org.

FT-NMR Spectrometer (2001) Spectroscopy 16: 47.

Gauri Shankar V, Venkata Raman Rao P, Reddy V (2010) Heterosis studies in castor, Ricinus communis L. Journal of Oilseeds Research 27: 95-96.

Gopani DD, Kabaria MM, Patel RH (1968) Studies of hybrid vigour in castor. Indian Journal of Agricultural Sciences 38: 520-527.

Graffius JE (1956) Components of yield in oats; a geometrical interpretation. Journal of Agronomy 4: 419-423.

Kavani RH, Padhar PR, Chovatia VP, Patel MB, Dobaria KL (2010) Heterosis and combining ability analysis for seed yield and its components in castor (Ricinus communis L.). Journal of Oilseeds Research 27: 105-107. 
Kempthorne O (1957) An introduction to genetic statistics. John Willey and Sons. Ind., New York Pp. 468-470.

Panse VG, Sukhatme PV (1969) Statistical Methods for Agricultural Workers. Indian Council of Agricultural Research, New Delhi.

Patel AR, Patel BN, Dhoshi JS, Patel JB and Patel JA (2010) Heterosis for seed yield and its components over environments in castor (Ricinus communis L.).Journal of Oilseeds Research 27: 53-56.

Patel DK, Chaudhari FP, Patel MS, Prajapati KP (2008a) Combining ability for yield and its components in castor, Ricinus communis L. Journal of Oilseeds Research 25: 200202.

Patel JB, Pathak HC (2006) Heterosis for seed yield per plant and its components in castor (Ricinus communis L.).Journal of Oilseeds Research 23: 93-95.

Patel PC, Dadheech A, Dave PB, Makani AY (2015) Heterosis and combining ability for yield and yield component traits in castor (Ricinus communis L.). Green Farming 6: 970-973.

Patel PS, Chaudhary YV, Joshi V (2008b) Genetic analysis of quantitative traits in castor, Ricinus communis L. Journal of Oilseeds Research 25:203-205.

Purohit B, Dadheech A, Patel BN, Patel JA (2010) Heterosis for seed yield and its components in castor Ricinus communis L. Journal of Oilseeds Research 27: 33-34.

Ramesh M, Lavanya C, Sujatha M, Sivasankar A, ArunaKumari J, Meena HP (2013) Heterosis and combining ability for yield and yield component traits of newly developed castor (Ricinus communis L.). Bioscan 8: 1421-1424.

Sapovadiya MH, Dobariya KL, Babariya CA, Mungra KS, Vavdiya PA (2015) Heterosis for seed yield and its components over environments in castor (Ricinus communis L.). Electronic Journal of Plant Breeding 6: 1118-1123.

SAS (2004) SAS Institute Inc., SAS 9.4 Help and Documentation, Cary, NC: SAS Institute Inc., 2002-2004.

Sharma JR (1994) Principles and Practices of Plant Breeding. Tata McGraw-Hill Publishing Co., Ltd., New Delhi.

Singh RK, Chaudhary BD (1985) Biometrical methods in quantitative genetic analysis. Kalyani publishers, New Delhi.

Sprague GF, Tatum LA (1942) General verses specific combining ability in single crosses of corn. Journal of American Society of Agronomy 34: 923-932.

Sridhar V, Dangi KS, Reddy AV, Sudhakar R, Sankar AS (2008) Heterosis for seed yield and yield components in castor (Ricinus communis L.). International Journal of Agricultural Biosciences 2: 64- 67 .

Thakker DA, Jadon BS, Patel KM, Patel CJ (2005) Heterosis over environments for seed yield and other attributes in castor, Ricinus communis L. Journal of Oilseeds Research 22: 324326.

Venkata Raman Rao P, Gauri Shankar V, Reddy V (2010) Combining ability analysis in castor Ricinus communis $\mathrm{L}$. Journal of Oilseeds Research 27: 102-104. 